\title{
O IMPACTO DO INVESTIMENTO EM SEGURANÇA PÚBLICA NA TAXA DE HOMICÍDIOS NO BRASIL
}

\section{THE IMPACT OF PUBLIC SECURITY INVESTMENT ON THE HOMICIDE RATE IN BRAZIL}

\author{
${ }^{1}$ Marcos Dias de Oliveira \\ ${ }^{2}$ Hector Luís Cordeiro Vieira
}

\section{RESUMO}

O tema abordado foi a eficiência dos investimentos públicos na redução da taxa de criminalidade no Brasil. O problema de pesquisa visava a investigar qual o impacto dos investimentos públicos na atividade policial sobre a redução da taxa de homicídios no país. Utilizando desenho quantitativo, foram testadas quatro hipóteses envolvendo a taxa de habitantes por policial militar, o investimento em policiamento, o investimento em segurança pública e o nível salarial dos policiais militares. Todas as hipóteses foram rejeitadas, sugerindo que os investimentos públicos na área de segurança não estão produzindo resultados efetivos.

Palavras-chave: Segurança pública, Polícia, Investimento público, Taxa de homicídios

\begin{abstract}
The broached topic was the efficiency of public investment on decreasing crime rate in Brazil. The research problem was aimed at investigating what was the impact of public investment in police activities on the decreasing of homicide rates in the country. Using a quantitative design, four hypotheses were tested, involving the rate of inhabitants per police officer, the investment in policing, the investment in public security, and officers' pay levels. All hypotheses were rejected, suggesting that public investment in security is not producing effective results.
\end{abstract}

Keywords: Public security, Police, Public investment, Homicide rate

\footnotetext{
${ }^{1}$ Doutor em Commerce pela University of Birmingham, BIRMINGHAM, Inglaterra.

E-mail: mddoliveira@gmail.com

${ }^{2}$ Doutorando em Direito na Universidade de Brasília, UnB. Professor do Centro Universitário do Distrito Federal -

UDF, Brasília - DF (Brasil). E-mail: vclhec@yahoo.com.br
} 


\section{INTRODUÇÃO}

O Portal G1-Globo (2015) noticiou que, na noite de 28 de novembro de 2015, cinco jovens foram executados dentro de um carro, no Rio de Janeiro. Aparentemente, eles se dirigiam a uma lanchonete na comunidade Costa Barros, quando o carro em que se encontravam foi alvejado por trios de metralhadora. Policiais militares são suspeitos de efetuar os disparos e alterar a cena do crime.

Esse tipo de violência é apenas uma entre tantas modalidades de homicídio que acontecem com tal frequência no Brasil que já nem causam espanto a quem se depara com a notícia. Ocorreram ao menos 58.497 mortes violentas no Brasil em 2014 (FÓRUM BRASILEIRO DE SEGURANÇA PÚBLICA, 2015).

Fatos como o relatado acima ocorrem por despreparo da polícia? Uma das hipóteses testadas por Oliveira (2007), em sua dissertação de mestrado, referia-se ao grau de segurança com o qual o policial sai da academia no Distrito Federal. O autor relata que $76,2 \%$ dos policiais militares se sentem apenas parcialmente seguros ou não se sentem seguros ao concluir seu curso de formação, enquanto $16,2 \%$ relatam não ter recebido instruções adequadas (para o serviço).

Seria de se esperar que o Estado, na condição de órgão detentor de todo o poder e encarregado do bem-estar do cidadão, estivesse se movimentando para implementar políticas de prevenção e combate à violência, incluídos os homicídios. Tais políticas deveriam envolver não apenas a qualidade do treinamento e do preparo psicológico dos policiais para o exercício da função, mas também de alocação de recursos para fazer frente às soluções desenhadas por especialistas em segurança.

Alguns Estados, com efeito, anunciam que estão investindo recursos em segurança pública, para melhor treinar e equipar as polícias, além de incrementar a presença policial junto à população.

Os resultados de tais políticas, no entanto, ainda é incerto. Os números de 2014 apontam para um aumento nos números de crimes, em vez de sua redução. O Brasil, culturalmente, carece de planejamento, notadamente na área pública. Fatos e dados nem sempre são levados em consideração para embasar políticas públicas, diferentemente do que costumeiramente ocorre em países de tradição anglo-saxã. 
No entanto, para que se possa saber se qualquer política pública que envolva investimento, ações direcionadas, alocação de recursos, entre outras ações inerentes à prerrogativa estatal de zelar pela sociedade, está surtindo efeito, faz-se necessária a análise de seus resultados, por meio de avaliação qualitativa e, sobretudo, medição periódica.

Infelizmente, no Brasil a produção de dados e o cruzamento de dados que envolvam a temática da segurança pública em um sentido mais amplo é bastante deficitário. Apenas há poucos anos é que certos dados começaram a tomar publicidade suficiente para embasar pesquisas e investimentos por parte da Administração Pública.

Tal avaliação é o tema central deste artigo, que visa a lançar alguma luz sobre o problema da eficiência do investimento de recursos públicos sobre a melhora da segurança da sociedade.

O objetivo deste artigo é, portanto, investigar qual o impacto dos investimentos públicos no aparato policial sobre a redução do número de homicídios no Brasil.

A importância do tema justifica-se pelo crescente aumento da violência no Brasil que, ainda que aparentemente acirrado em anos recentes (WAISELFISZ, 2011), é objeto de discussão há décadas, já tendo sido equiparado a problemas de saúde pública nos anos oitenta (SOUZA, 1994). Cabe ressaltar, ainda, a estreita relação da violência urbana, notadamente as taxas de homicídios, com a deterioração econômica da população mais carente, conforme demonstrado por Andrade e Lisboa (2000), além da pouca densidade e ambiguidade semântica das proposições normativas da Constituição Federal de 1988 (LINS, 2011).

A abordagem metodológica se valeu de desenho quantitativo, o que possibilitou o teste de quatro hipóteses envolvendo a taxa de habitantes por policial militar, o investimento em policiamento, o investimento em segurança pública em sentido mais amplo e o nível salarial dos policiais militares.

\section{REDEFININDO OS MARCOS DA VIOLÊNCIA}

O uso do aparato policial é considerado um dos meios de controle social que o Estado exerce sobre a sociedade. Controle social é entendido como a capacidade da sociedade de se autorregular de acordo com princípios e valores desejado (COSTA, 2003; BERGER, 2001). Mas também é necessário considerar aspectos que geram conflito, o que impede que o controle social estabeleça a ordem social e a estabilidade das relações sociais. 
A "noção de controle social parte das noções de consciência coletiva, crime e anomia. Aqui é dada a primazia à sociedade sobre o indivíduo" (COSTA, 2003, p. 50). Se do ponto de vista psicológico o crime é visto como uma patologia, ele, como objeto de estudo da sociologia, é um fato social normal, que ocorre em todas as sociedades. Com efeito, "o crime, para Durkheim, é 'todo ato que ofende certos sentimentos coletivos'; apesar de sua natureza aparentemente patológica, não deixa de ser considerado como um fenômeno normal. ${ }^{1}$ Grosso modo, o crime pode ser tratado como a 'dor' da sociedade" (SILVA, 2009, p. 22).

O controle social está ligado ao conjunto da sociedade e ao Estado, como órgão central de controle. O Estado possui o monopólio do uso da violência legítima, o que é fundamental para a ideia de controle social. Com isso em mente, pode-se pensar que a violência privada, aquela não sancionada pelo Estado, seria uma forma de rompimento daquele controle, que pode ser atribuído à fragilidade e à insuficiência dos instrumentos de controle social.

A população espera que a força, como monopólio estatal, seja utilizada para promover a segurança da sociedade, formando uma barreira entre ela e os elementos que possam causar-lhe dano. Na verdade, mais que isso, haja vista que segurança integra o conjunto de direitos e garantias fundamentais abrangidos Constituição Federal que, em seu art. 144, determina que "A segurança pública, dever do Estado, direito e responsabilidade de todos, é exercida para a preservação da ordem pública e da incolumidade das pessoas e do patrimônio, através dos seguintes órgãos: [...]” (BRASIL, 1988) [grifo nosso]. Todavia, a crescente onda de violência que se observa no Brasil nas últimas décadas parece apontar para certo grau de fracasso do Estado no papel de promotor da segurança social.

As relações entre a sociedade civil e o aparelho repressivo estatal, no Brasil, parecem ocorrer mais de modo mais conflituoso do que em países mais desenvolvidos. Essas relações se dão de inúmeras formas. Em democracias liberais, pode ocorrer uma separação entre Estado e sociedade civil; nesse caso, a sociedade está sob controle privado, e o estado limitase basicamente à sua função coercitiva, enquanto em "países de ideologia menos democrática e humanitária os instrumentos de violência são exibidos - e empregados - com muito menos discrição" (BERGER, 2001, p. 82).

\footnotetext{
${ }^{1}$ Para mais sobre a discussão em Emile Durkheim, ver: DURKHEIM, Émile. As Regras do Método Sociológico. Tradução de Pietro Nassetti- Ed. Martin Clareto - São Paulo, 2007.
} 
No Brasil, principalmente nas comunidades de baixa renda, a intervenção do aparato policial é mais frequente e marcante, chegando mesmo a fazer parte do dia-a-dia da população. Essa interação atinge tal ponto que não é incomum a contratação de policiais ou ex-policiais para fornecer proteção a comerciantes contra assaltantes, como se observa na Baixada Fluminense (LIMA, 1995).

A Constituição Federal de 1988 trouxe avanços democráticos inegáveis, mas nem todo tipo de direito fez parte da instauração plena do Estado de direito. Segundo Bueno (2014), a violência endêmica radicada nas estruturas sociais evidenciou a incapacidade estatal de garantir o controle legal da violência. Para a autora,

\begin{abstract}
O campo da segurança pública não sofreu as reformas necessárias para garantir que sua arquitetura institucional, saberes e práticas funcionassem em sintonia com o novo modelo vigente. Ao contrário, destaca-se a continuidade de muitos elementos que continuaram a reproduzir relações que serviram a um governo ditatorial, e a segurança pública continuou a ser pensada apenas na lógica da atividade policial e do direito penal (BUENO, 2014, p.2)
\end{abstract}

É óbvio que mesmo entre os policiais que procuram exercer suas funções estritamente dentro do que é esperado deles, tanto pelo Estado como pela sociedade, a decisão de fazê-lo é quase que de sua exclusiva responsabilidade. Como apontado por Porto e Costa (2014, p. 8), "Possivelmente, dentre os agentes estatais, os policiais estão entre aqueles que possuem maior liberdade para exercer suas funções, tanto em termos do exercício da autoridade, quanto em relação aos controles a que estão submetidos".

Faz parte dessa liberdade a decisão de aplicar ou não lei. Quando faz uso dessa faculdade, o policial não está somente no seu papel de cumprir a lei, mas também tomando decisões de usá-la ou não.

\begin{abstract}
A polícia é responsável por fazer cumprir todas as leis. Mas na realidade o policial frequentemente tem de decidir se irá multar ou não um motorista apressado, prender ou não um marido violento, proibir ou não uma festa barulhenta, para citar apenas algumas situações. Ou seja, o policial pode de fato decidir aplicar a lei ou não (PORTO e COSTA, 2014, p. 81).
\end{abstract}

É interessante notar que há na literatura sobre a atuação policial a concepção de que o que as pessoas querem é uma ação rápida e, via de regra informal na situação de conflito. (OLIVEIRA, 1985). A procura por este modo de resolução de conflitos apresenta-se como "um dos capítulos da velha história da inacessibilidade do Judiciário a determinados tipos de casos e, consequentemente, da busca, pelos interessados, de locais alternativos para onde possam se dirigir"(OLIVEIRA, 1985. p. 93). Essa atuação policial é uma herança das atribuições 
dadas à polícia pelo Código Criminal do Império que dava competência para a instituição policial para apreciar pequenos delitos de natureza pessoal.

Em sociedades mais desenvolvidas, essa liberdade que o policial tem pode ser um ponto positivo, uma vez que ele consegue criar laços mais estreitos com muitas comunidades e sua presença constante nas ruas contribui efetivamente para coibir o crime. Mas em tais países é provável que a violência policial não seja tão resignadamente aceita como no Brasil. Basta lembrar os grandes protestos feitos por ocasião de abusos policiais que levaram à morte jovens negros, nos Estados Unidos (DW, 2014).

Uma das características que notamos no Brasil é que aqui a segurança pública é tratada como atividade baseada no pensamento e administração militares. Tal pensamento nunca conseguiu perceber que são diferentes os campos de atuação policial e militar, "não somente quanto à imagem do criminoso, mas sobretudo quanto ao terreno das operações policiais" (OLIVEIRA, 2007, p. 40).

Parece inegável que o modelo de controle social vigente em determinado país é determinante para a forma de atuação das polícias e suas tarefas cotidianas.

\footnotetext{
Desse modelo deriva uma série de práticas policiais, algumas delas consagradas nos estatutos, regulamentos e manuais de polícia. Outras, não menos importantes, incorporam-se à cultura institucional e são transmitidas pelos processos de socialização a que estão submetidos os membros das organizações policiais (COSTA, 2008, p.411).
}

Essa área cinzenta entre o que deveria ser escopo de atuação policial e não de atuação militar pode se manifestar no inconsciente coletivo do brasileiro como algo perigoso. Talvez venha daí a noção de que grande parte dos homicídios, no Brasil, é de responsabilidade de policiais em serviço. A insegurança que pode advir dessa percepção coloca o cidadão em situação de impotência perante o Estado. Segundo Oliveira,

Frente a ondas de criminalidade a sensação de segurança se vê diminuída aos olhos do cidadão, que mesmo com ressalvas e desconfianças de atuação de agentes policiais, clama, e na maioria das vezes não é ouvida por encontrar- se afastada dos processos, pelo cumprimento da lei e da ordem seja nas cidades seja nos campos (OLIVEIRA, 2007, p. 107).

No entanto, essa noção é equivocada. A percentagem de homicídios praticados por policiais é relativamente baixa, comparada a outras modalidades. Mesmo em número superior à percentagem encontrada em outros países, os homicídios praticados por policiais no exercício da função, no Brasil, "contribuem de forma secundária para o movimento geral dos homicídios" (RATTON JR., 1996, p 58). 
Em sua pesquisa, Ratton Jr. (1996, p. 50-51) classifica os homicídios em cinco grupos:

a) Homicídios de proximidade: relativos a pessoas que já se conhecem anteriormente e mantém relação de proximidade - amigos, inimigos, vizinhos, parentes etc.;

b) Homicídios por motivos fúteis: relativos a desentendimentos, confusões, brigas etc. entre indivíduos que resultam em homicídio;

c) Criminalidade de rua: relativos à criminalidade urbana propriamente dita, decorrentes de roubos e tentativas de roubos, ação e disputa de quadrilhas, ação de galeras, sequestros etc.;

d) Homicídios institucionais: relativos aos praticados por policiais militares, civis, federais, guardas municipais etc., em serviço;

e) Homicídios de extermínio: praticados por grupos de extermínio, esquadrões da morte, polícia mineira ${ }^{2}$ etc.

Os homicídios institucionais, aqueles que são causados por policiais em serviço, embora contribuam de modo secundário para o volume total de homicídios, têm a particularidade de ocorrer normalmente em comunidades de baixa renda (MISSE et alii, 2010).

Outra importante noção para refletir sobre a temática é a apresentada por Arthur Trindade M. da Costa que define três tendências de violência: crimes contra o patrimônio, criminalidade organizada e os conflitos intersubjetivos. Especialmente, para compor a discussão aquela que o autor se refere com sendo a dos conflitos intersubjetivos lança um exame a partir da ideia de que

o comportamento violento é visto como uma estratégia ilegítima para alcançar determinados objetivos. Por outro lado, estamos inclinados a pensar que os casos em que tais estratégias e objetivos não são claramente definidos como situações anormais ou irracio- nais, a violência está desprovida de sentido

\footnotetext{
${ }^{2}$ Contratação de policiais ou ex-policiais para fornecer proteção a comerciantes contra assaltantes, como se observa na Baixada Fluminense (LIMA, 1995).
} 
Isso talvez explique por que frequentemente nos re- ferimos a uma "violência sem sentido", quando não conseguimos reconhecer facilmente os mei- os e fins daquela ação.

Entretanto, ao invés de definir a violência a priori como irracional, nós deveríamos considerá-la como expressão de uma forma de interação. Uma forma de ação que foi histórica e socialmente construída e que é capaz de dar sen- tido e significado à violência. Qualificar a vio- lência como irracional, sem sentido ou significa- do, apenas reflete uma tendência de analisar os casos de violência dissociados do seu contexto. (COSTA, 2011, p. 357)

A prevenção da violência é assunto que extrapola fronteiras nacionais. Cerca de meio milhão de pessoas são assassinadas no mundo a cada ano. No entanto,

Não obstante a importância atribuída à "paz e segurança" durante a Rio+20 e consultas nas Nações Unidas desde 2012, a discussão sobre desenvolvimento é relativamente omissa sobre questões relacionadas ao espaço da prevenção e redução da violência na agenda pós-2015. [...] Objetivos e metas destinados a prevenir e reduzir a violência devem estabelecer parâmetros claros e orientar Estados e sociedades. As metas devem ser realistas, defensáveis e viáveis, mas também ambiciosas. Todavia, apesar de um grau relativamente elevado de consenso sobre o imperativo de prevenir e reduzir a violência para promover o desenvolvimento, há ainda desafios políticos, terminológicos e relativos aos dados pendentes (MUGGAH, 2013, p. 43).

Assim, é de esperar que a questão da prevenção à violência, particularmente aquela relativa a homicídios, seja encarada como assunto de políticas públicas, sejam elas de melhor preparo dos policiais, de aparelhamento da polícia ou de alocação de recursos suficientes para segurança pública, o que, espera-se, possa inverter a curva ascendente de homicídios no Brasil.

\section{CONEXÕES DO HOMICÍDIO E SUAS VARIÁVEIS: AS HIPÓTESES E A METODOLOGIA}

Uma das reclamações da população é que, em muitas áreas, não há policiais suficientes. Disso resultaria a facilidade para criminosos agirem contra o patrimônio ou contra a vida das pessoas. O senso comum é o de que quanto maior o número de policiais presentes, maior a segurança em determinada comunidade. Assim, o ideal seria que o número de habitantes por policial fosse o menor possível, propiciando a cada policial que tivesse um número menor de cidadãos sob seus cuidados. 
H1: Quanto menor a taxa de habitantes por policial militar ${ }^{3}$ menor a taxa de homicídios.

Parece ser senso comum que o policiamento ostensivo, regular, pode coibir o crime. Para que isso aconteça, é necessário que a atividade de policiamento propriamente dita receba atenção especial das autoridades. É preciso investir em equipamentos de segurança, armas e veículos especialmente destinados ao policiamento. Daí deriva a ideia de que mais policiamento traz mais segurança à sociedade.

H2: Quanto maior a taxa de investimento por habitante em policiamento, menor a taxa de homicídios.

A atividade policial, todavia, não se reduz ao policiamento. Outras ações de segurança pública podem contribuir para maior eficiência das ações de prevenção e combate ao crime. A segurança pública inclui o policiamento, mas vai além. Também envolve ações de treinamento, intercâmbio policial, campanhas junto à população, investimento na modernização da administração pública e nos equipamentos de uso em serviço e de treinamento, interação com o judiciário, ações de integração entre polícia civil, militar, federal e guardas municipais, entre outras ações que podem incrementar a eficiência da segurança pública.

H3: Quanto maior a taxa de investimento por habitante em segurança pública, menor a taxa de homicídios.

Parece senso comum que qualquer trabalhador tem melhor desempenho se estiver satisfeito com seu salário. No entanto, Dick e Ellis (2006), explicando a teoria dos dois fatores de Herzberg, afirmam que salário não é um fator de motivação, mas sim de prevenção de insatisfação. Em outras palavras, se o trabalhador estiver satisfeito com seu salário, aumentálo não vai motivá-lo ainda mais. Porém, se estiver insatisfeito, sentir-se-á desmotivado. Prevenir a insatisfação é, dessa forma, o objetivo de pagar salários adequados. Isso não é diferente para os policiais, que podem ver no salário um dos atrativos para ingressar e evoluir na carreira. Considerando que a evolução salarial é proporcional ao salário inicial, este é representativo para os demais níveis.

\footnotetext{
${ }^{3}$ Policiais militares foram utilizados como representantes da força policial porque, como estão no início do ciclo policial, estão em contato mais próximo com a sociedade, realizando, por exemplo, policiamento ostensivo, o que, em tese, deveria ser instrumento para coibir violência urbana, aí incluídos os homicídios. É de competência da Polícia Militar "Planejar, organizar, dirigir, supervisionar, coordenar, controlar e executar as ações de polícia ostensiva e de preservação da ordem pública" (TOCANTINS, 2015). Além disso, o art. 144-IV-\$5 da Constituição Federal determina que "Às polícias militares cabem a polícia ostensiva e a preservação da ordem pública; [...]" (BRASIL, 1988).
} 
H4: Quanto maior o salário inicial de um soldado da Polícia Militar menor o número de homicídios.

O desenho escolhido foi o quantitativo, porque o que se visa a analisar é o efeito direto de quatro variáveis quantitativas independentes sobre uma dependente, a taxa de homicídios. Como o objetivo é explorar possíveis relações entre as variáveis, o desenho experimental, quantitativo, é o que se mostra mais adequado (CRESWELL, 2003). Foram utilizados dados dos 26 Estados e do Distrito Federal para 2011 (FÓRUM BRASILEIRO DE SEGURANÇA PÚBLICA, 2012) e 2012 (FÓRUM BRASILEIRO DE SEGURANÇA PÚBLICA, 2013)4.

Como exposto no tópico anterior, homicídios pertencem a diferentes categorias e, desse modo, medir apenas a taxa de homicídios dolosos na população revelaria informação incompleta do quadro. A taxa de homicídios, portanto, é representada pela categoria Crimes Violentos Letais Intencionais (CVLI), que agrega as ocorrências de Homicídio Doloso, Latrocínio e Lesão Corporal seguida de Morte, conforme descrito no Anuário Brasileiro de Segurança Pública (FÓRUM BRASILEIRO DE SEGURANÇA PÚBLICA, 2013), de onde foram retirados também os dados para as variáveis independentes. A taxa foi obtida dividindo-se o número de CVLI pela população de cada Estado, conforme dados divulgados pelo IBGE (2015) relativos ao censo de 2010,

De acordo com Arthur Trindade,

Desde 2007, quando o Fórum Brasileiro de Segurança Pública começou a sistematizar as estatísticas dos crimes violentos letais e intencionais (CVLI), as taxas de homicídios do Brasil têm variado pouco. Entre 2005 e 2012 a taxa aumentou de 22,5 para 24,3 homicídios para cada grupo de 100 mil habitantes. Uma pequena variação de $8 \%$, se comparada com a variação de $127 \%$ verificada entre os anos de 1980 e 2004. Este quadro, entretanto, pode dar a falsa impressão de que ocorreram poucas mudanças nos últimos anos (COSTA, 2013, p. 31).

A taxa de investimento em policiamento foi obtida dividindo-se o valor total investido em reais pela população de cada Estado e é representada, na equação, pela sigla GASTOP.

A taxa de investimento em segurança pública foi obtida dividindo-se o valor total investido em reais pela população de cada Estado. Gastos com segurança pública incluem os

\footnotetext{
${ }^{4} \mathrm{O}$ relatório de 2015 trazia dados mais recentes, mas somente para duas das variáveis; para que fosse possível manter todas elas no estudo, a coleta limitou-se a 2011 e 2012.
} 
gastos com policiamento, aos quais se somam gastos com defesa civil, informação e inteligência e demais subfunções; foi representada pela sigla GASTOT.

A maior ou menor presença de policiais militares em cada Estado foi medida pela taxa de habitantes por policial militar, o que incluiu não apenas os soldados, mas todas as faixas, como oficiais, praças e agentes, aspirante a oficial, cadete, aluno-oficial e aluno- soldado; representada pela sigla EFETIVO.

As informações sobre salário referem-se à remuneração inicial bruta de um soldado da Polícia Militar e foi representada pela sigla SALARIO.

Os dados foram analisados por meio de pacote estatístico comumente utilizado na pesquisa em ciências sociais, o SPSS, na sua versão 21. A técnica escolhida foi análise de regressão que, segundo Malhotra e Birks, "é um procedimento poderoso e flexível para analisar relações associativas entre uma variável métrica dependente e uma ou mais variáveis independentes" (MALHOTRA, 2006, p. 519) 5 .

\section{ANÁLISE DE RESULTADOS E DISCUSSÃO}

Os dados analisados foram retirados de tabelas apresentadas nos relatórios do Fórum Brasileiro de Segurança Pública (2012, p. 72-73; 76-77; 2013, p. 28-29; 44-45; 72-75). O método estatístico utilizado, análise de regressão, testa o quanto cada uma das variáveis independentes ${ }^{6}$ explica a variação na taxa de homicídio, tanto considerada isoladamente quanto na presença das outras três, agindo em conjunto.

O teste parte da hipótese de que cada variável independente não tem nenhuma relação com a taxa de homicídios, ou seja, qualquer discrepância que ela possa causar na medida da variável dependente deve-se unicamente à variação estatística ou, popularmente, "ao acaso".

Só é possível rejeitar essa hipótese, chamada de hipótese nula, se a probabilidade de que os resultados encontrados representem uma influência real de cada variável independente

\footnotetext{
5 Tradução livre do autor.

${ }^{6}$ Variável independente é aquela que não depende de nenhuma outra para ter seu valor determinado, mas pode ter influência sobre a variável isolada que se testa, chamada, por isso, de dependente (no caso em tela, a taxa de homicídios).
} 
sobre a variável dependente for maior que 95\%; caso contrário, não é possível afirmar que aquela variável independente produz efeito sobre a variável dependente.

Essa probabilidade é chamada de nível de significância e é calculada pela diferença de $100 \%$. Portanto, para que se possa afirmar que há influência de uma variável sobre outra, o nível de significância tem de ser menor que $5 \%$, ou 0,05 . Como pode ser visto na tabela 1 , todos os níveis de significância encontrados são maiores do que 0,05 (última coluna à direita, dentro da área cinza).

Tabela 1: Análise de regressão - fatores com possível impacto na taxa de homicídio.

Testes de efeitos entre assuntos

Variável dependente: CVLI

\begin{tabular}{|l|r|r|r|r|r|}
\hline Fonte & $\begin{array}{c}\text { Tipo III Soma } \\
\text { dos } \\
\text { Quadrados }\end{array}$ & df & \multicolumn{1}{c|}{$\begin{array}{c}\text { Quadrado } \\
\text { Médio }\end{array}$} & \multicolumn{1}{c|}{ F } & \multicolumn{1}{|c|}{ Sig. } \\
\hline Modelo corrigido & $509,262^{\text {a }}$ & 4 & 127,315 &, 684 &, 606 \\
Ordenada na origem & 2299,235 & 1 & 2299,235 & 12,353 &, 001 \\
GASTOP & 243,411 & 1 & 243,411 & 1,308 &, $\mathbf{2 5 8}$ \\
GASTOT & 486,562 & 1 & 486,562 & 2,614 &, $\mathbf{1 1 2}$ \\
EFETIVO & 95,046 & 1 & 95,046 &, 511 &, $\mathbf{4 7 8}$ \\
SALARIO & 6,757 & 1 & 6,757 &, 036 & $\mathbf{8 5 0}$ \\
Erro & 9120,594 & 49 & 186,135 & & \\
Total & 52014,549 & 54 & & & \\
Total corrigido & 9629,856 & 53 & & & \\
\hline
\end{tabular}

a. $\mathrm{R}$ ao quadrado $=, 053(\mathrm{R}$ ao quadrado ajustado $=-, 024)$

A tabela 2 mostra o resultado das hipóteses testadas. 
Tabela 2. Resultado das hipóteses testadas por análise de regressão

\begin{tabular}{|c|c|}
\hline Hipótese & Resultado \\
\hline $\begin{array}{l}\text { H1: Quanto menor a taxa de habitantes por policial militar menor a taxa de } \\
\text { homicídios. }\end{array}$ & Rejeitada \\
\hline $\begin{array}{l}\mathrm{H} 2 \text { : Quanto maior a taxa de investimento por habitante em policiamento, menor } \\
\text { a taxa de homicídios. }\end{array}$ & Rejeitada \\
\hline $\begin{array}{l}\text { H3: Quanto maior a taxa de investimento por habitante em segurança pública, } \\
\text { menor a taxa de homicídios. }\end{array}$ & Rejeitada \\
\hline $\begin{array}{l}\text { H4: Quanto maior o salário inicial de um soldado da Polícia Militar menor o } \\
\text { número de homicídios. }\end{array}$ & Rejeitada \\
\hline
\end{tabular}

Os dados sugerem, portanto, que as ações do poder público para propiciar mais policiais militares para promover a segurança da população, bem como o investimento em policiamento e outras áreas da segurança pública não parecem estar surtindo efeito; tampouco está o nível salarial pago aos soldados da Polícia Militar.

Uma das possíveis explicações para tal ineficiência pode ser a disputa entre instituições, bem como a falta de integração entre elas. À medida que o ciclo policial avança, os casos passam das mãos dos policiais militares para as mãos dos policiais civis. Com não há integração entre as polícias, pode haver uma sensação de que o policial militar deixou seu trabalho pela metade, já que não tem a oportunidade de acompanhar o desenvolvimento do caso que se iniciou com ele.

A já citada falta de planejamento eficaz característica do Estado brasileiro, no entanto, parece ser uma razão mais plausível para justificar os resultados encontrados. Como não é costume relacionar as lições aprendidas com experiências passadas, o planejamento raramente leva em conta uma sucessão de resultados que estão interligados e que poderiam jogar luz sobre possíveis melhorias no sistema. É como se, no Brasil, todos estivessem sempre contando com a sorte. 
Nesse sentido, Lima e Bueno (2015) sugerem que o Estado tem optado por manter um sistema fracamente articulado, dissipando suas energias em disputas entre instituições. Os autores afirmam que

Vivemos ofuscados pela violência e num eterno presente, que teima em não aprender com as lições do passado e insiste em acreditar que o futuro "somente a Deus pertence". Ficamos à espera de um salvador. É mais fácil matar o mensageiro - no caso, recusar dar transparência e prestar contas à sociedade do que ter coragem política e disposição para fazer diferente (LIMA e BUENO, 2015, p. 8-9).

Como pode ser visto, também não existe transparência na prestação de contas à sociedade, nem em relação aos recursos financeiros despendidos em segurança pública, nem em sua alocação e muito menos na divulgação de dados minimamente confiáveis a respeito dos resultados obtidos com aqueles recursos.

A articulação entre a esfera política e a corporação policial ocorre de maneira precária. Exemplo disso foi o recente episódio de agressão aos professores em greve no Distrito Federal, cuja ordem partiu do comando-geral da Polícia Militar, sem que tenham sido consultados nem o Secretário de Segurança Pública, nem o Governador. (EBC, 2015) Como mostra de força da corporação, o comandante foi mantido no cargo, enquanto o Secretário pediu exoneração. Nem mesmo a cadeia de comando, algo central no comportamento militar, foi respeitada pelos oficiais ${ }^{7}$.

Mataram-se no Brasil em 2014 tantas pessoas quantos foram os soldados americanos mortos em toda a Guerra do Vietnam. De nada adiantaram os investimentos feitos em policiamento, segurança pública e salários da força policial. Por mais grave que se apresente o quadro da violência no país, não se consegue incluir o tema no centro da agenda política

7 A título de reflexão, cabe salientar trecho da carta de exoneração do então Secretário de Segurança, Arthur Trindade M. Costa: "A ação da PMDF contra os professores foi equivocada, do meu ponto de vista. Todos os especialistas que consultei foram unânimes em dizer que houve uso desproporcional da força e que não foram esgotadas as negociações. Pior, a ação foi dirigida diretamente pelo comandante geral, sem consultar o governador ou o secretário de segurança. Sou professor e tenho uma trajetória em segurança pública e direitos humanos. Não posso concordar com o que aconteceu. Precisamos decidir qual polícia queremos. Uma polícia cidadã ou uma polícia que não se submete a autoridade civil e tem dificuldades para admitir seus erros? Os erros na ação da semana passada não podem, de forma alguma, ser atribuídos aos policiais do Batalhão de Choque. São profissionais que seguem protocolos. Se os protocolos estão equivocados, cabe ao comando corrigi-los. Mais do que erros pontuais, a ação revelou as graves falhas na cadeia de comando e na estrutura de governança da segurança pública do Distrito Federal. Desde o início dos nossos trabalhos, temos encontrado dificuldades de trabalhar com alguns setores da PMDF. Para estes, prevalece a ideia de que a polícia é autônoma e não precisa se submeter as diretrizes da Secretaria de Segurança Pública. Eles não querem uma Secretaria forte e capaz de planejar uma política de segurança pública. O Distrito Federal tem, em termos proporcionais, o maior orçamento de segurança pública do país. Tem também os maiores efetivos proporcionais. Nossas policiais são bem pagas. Mas apesar disso, historicamente as entregas na área de segurança pública têm sido pífias. Nossa taxa de homicídios é alta, a população segue insegura, desconfia das polícias e os serviços de polícia deixam a desejar. Tudo isso porque falta uma secretaria de fato capaz de ditar uma política de segurança." (CONGRESSO EM FOCO, 2015) 
brasileira. O problema, de dimensões gigantes, costuma ser tratado com atenção apenas mediana e imediatista pela imprensa, pela sociedade e pelo governo.

A esse respeito, Abramovay (2015) declarou que

\begin{abstract}
A única explicação razoável para essa epidemia de indiferença diante do horror é o fato de que os mortos são invisíveis. São quase todos pobres, são em grande parte negros e jovens. Nesse sentido, é fundamental que se consiga visibilizar o invisível, que se fure o bloqueio do silêncio cômodo frente a uma quantidade inaceitável de mortes. O Brasil, que conseguiu enfrentar com sucesso temas complexos como a inflação, a mortalidade infantil e a fome, mostra-se inerte frente à calamidade dos homicídios. A situação é tão grave que não se pode adiar o início da reversão desses números. E conhecendo a escala do problema, é sabido que apenas um amplo pacto nacional terá o condão de atacá-lo (ABRAMOVAY, 2015, p.

20-21).
\end{abstract}

Tal pacto necessitaria de muita vontade política, muito compromisso de diversos setores da sociedade organizada, de ação orquestrada entre governo e sociedade civil, de estipulação de metas para redução de homicídios, de metas para inclusão social, de transparência na prestação de contas, enfim, de muito planejamento. Algo que o Estado brasileiro não aprendeu a valorizar.

\title{
4 CONCLUSÕES
}

Diante da discussão trazida pelo texto, é preciso aprofundar as bases de reflexão acerca da questão da segurança pública no Brasil. Isso implica em aceitar que o reducionismo feito, via de regra, em análises que conectam diretamente os fatores de investimento a um resultado positivo imediato e concreto sobre a violência não satisfaz o conjunto explicativo possível para o que a empiria tem mostrado.

Parece, portanto, que não apenas a discussão sobre o impacto dos investimentos em segurança pública nas taxas de homicídios precisa ser repensada. Há, de fato, uma necessidade em se rearticular os fatores e variáveis que influenciam diretamente na percepção da violência na sociedade brasileira. Fatores esses que podem ter múltiplas origens de caráter sociológico como, por exemplo, a cultura policialesca e da ampla dependência do Estado na resolução de conflitos no Brasil.

Especificamente, no que toca ao objeto desse artigo, a primeira conclusão é a de que os investimentos feitos pelos governos estaduais e o Distrito Federal em segurança pública, aí 
destacada o policiamento, não estão dando resultado. Se, em teoria, policiais militares estivessem sendo mais bem treinados com tais recursos, equipamentos melhores e mais modernos estivessem sendo adquiridos, e os serviços de informação e inteligência tivessem sido aprimorados, o combate ao crime deveria estar obtendo melhores resultados.

A segunda conclusão é que também não houve melhora nas taxas de homicídio com o aumento da taxa de policiais militares em relação à população. A rigor, a presença de mais policiais disponíveis para prevenir e combater a violência deveria ter impacto na sua redução. Os dados parecem indicar que o aumento quantitativo no contingente policial não significa aumento na qualidade dos serviços prestados por eles.

A terceira conclusão é que os níveis salariais pagos aos policiais militares não parecem trazer motivação a eles; tampouco sua melhora parece afastar a desmotivação. Se não adianta pagar mais, que outras medidas podem ser tomadas para motivar a tropa?

De modo geral, todo e qualquer investimento feito em segurança pública no Brasil parece estar sendo desperdiçado, se o objetivo é alcançar a redução na taxa de CVLI no país. A taxa, ao contrário, está aumentando. Vale lembrar que, em 2014, em nenhum país do mundo sem guerra declarada se matou tanto quanto no Brasil. Campeão, mais uma vez.

\section{REFERÊNCIAS BIBLIOGRÁFICAS}

ABRAMOVAY, Pedro. Um pacto para vencer nossa maior tragédia desde a escravidão. In FÓRUM BRASILEIRO DE SEGURANÇA PÚBLICA. Anuário Brasileiro de Segurança Pública. Ano 9, 2015. Disponível em http://www.forumseguranca.org.br/produtos/anuariobrasileiro-de-seguranca-publica/9o-anuario-brasileiro-de-seguranca-publica.

ANDRADE, Mônica Viegas e LISBOA, Marcos de Barros. Desesperança de vida: homicídio em Minas Gerais, Rio de Janeiro e São Paulo: 1981 a 1997. Anais do IX Seminário sobre a Economia Mineira. Diamantina, 29 ago. a $1^{\text {o }}$ set. 2000, p. 775-808. Disponível em http://www.cedeplar.face.ufmg.br/diamantina2000/2000/LISBOA.pdf. Acesso em 21 mar. 2016.

BERGER, Peter L. Perspectivas Sociológicas: uma visão humanística. 23. ed. Petrópolis: Vozes, 2001.

BRASIL. Constituição da República Federativa do Brasil de 1988. Disponível em http://www.planalto.gov.br/ccivil_03/constituicao/ConstituicaoCompilado.htm. Acessado em 8 abr. 2016. 
BUENO, Samira. Quando a Polícia Mata: Refletindo sobre a Permanência de Práticas Violentas no Cotidiano da Polícia Militar do Estado de São Paulo. XXXVIII EnANPAD. Rio de Janeiro, 13 a 17 set. 2014.

COSTA, Arthur Trindade Maranhão. Estado, Polícia e Democracia. Tese de Doutorado. Brasília: UnB, 2003.

As reformas nas polícias e seus obstáculos: Uma análise comparada das interações entre a sociedade civil, a sociedade política e as polícias. Civitas, Porto Alegre, v. 8, n. 3, p. 409-427, set.-dez. 2008

. É possível reverter a espiral da violência. In FÓRUM BRASILEIRO DE SEGURANÇA PÚBLICA. Anuário Brasileiro de Segurança Pública. Ano 7, 2013. Disponível em http://www.forumseguranca.org.br/produtos/anuario-brasileiro-de-segurancapublica/7a-edicao.

CRH, Violências e conflitos intersubjetivos no Brasil contemporâneo. Cad. http://www.scielo.br/scielo.php?script=sci_arttext\&pid=S0103-

$49792011000200008 \& \operatorname{lng}=\mathrm{en} \& \mathrm{nrm}=$ iso . Acessado em 28 mar. 2016.

CONGRESSO EM FOCO. Secretário de Segurança Pública do DF pede demissão. Disponível em http://congressoemfoco.uol.com.br/noticias/secretario-de-seguranca-publicado-df-pede-demissao/. Acessado em 27 mar. 2016.

CRESWELL, John W. Research Design: Qualitative, Quantitative, and Mixed Design Approaches. Londres: Sage, 2003.

DICK, Penny e ELLIS, Steve. Introduction to Organizational Behaviour. 3. ed. Londres: McGraw-Hill, 2006.

DW. Entenda o Caso Michael Brown e os protestos em Ferguson. 2014. Disponível em http://www.dw.com/pt/entenda-o-caso-michael-brown-e-os-protestos-em-ferguson/a17861142. Acessado em 30 mar. 2016.

EBC Agência Brasil. Manifestação de servidores do DF termina em confronto com a polícia. Disponível em http://agenciabrasil.ebc.com.br/educacao/noticia/201510/manifestacao-de-servidores-termina-em-confronto-com-policia. Acessado em 27 mar. 2016.

FÓRUM BRASILEIRO DE SEGURANÇA PÚBLICA. Anuário Brasileiro de Segurança Pública. Ano 6, 2012. Disponível em http://www.forumseguranca.org.br/produtos/anuariobrasileiro-de-seguranca-publica/6a-edicao.

Anuário Brasileiro de Segurança Pública. Ano 7, 2013. Disponível em http://www.forumseguranca.org.br/produtos/anuario-brasileiro-de-seguranca-publica/7aedicao. 
IBGE. Censo Demográfico de 2010. Disponível em http://www.ibge.gov.br/home/estatistica/populacao/censo2010/. Acessado em 10 nov. 2015.

LIMA, Renato Sérgio de e BUENO, Samira. O eterno presente da segurança pública brasileira. In FÓRUM BRASILEIRO DE SEGURANÇA PÚBLICA. Anuário Brasileiro de Segurança Pública. Ano 9, 2015. Disponível em http://www.forumseguranca.org.br/produtos/anuario-brasileiro-de-seguranca-publica/9oanuario-brasileiro-de-seguranca-publica.

LIMA, Roberto Kant de. A Polícia na Cidade do Rio de Janeiro. Rio de Janeiro: Forense, 1995.

LINS, Bruno Jorge Rijo Lamenha. Breves reflexões sobre segurança pública e permanências autoritárias na Constituição Federal de 1988. Revista de Direito Brasileira. V. 1, n. 1: 173207, 2011.

MALHOTRA, Naresh K. e BIRKS, David F. Marketing Research: an Applied Approach. Londres: Prentice Hall/Financial Times, 2006.

MISSE, Michel et alii. O Inquérito Policial no Rio de Janeiro: mudanças recentes, alcances, tradições e especificidades. In MISSE, Michel (org.) O Inquérito Policial no Brasil. Rio de Janeiro: NECVU/IFCS/UFRJ; Booklink, 2010.

MUGGAH, Robert. Prevenção à violência e Agenda das Metas do Milênio e Desenvolvimento Pós-2015. In FÓRUM BRASILEIRO DE SEGURANÇA PÚBLICA. Anuário Brasileiro de Segurança Pública. Ano 7, 2013. Disponível em http://www.forumseguranca.org.br/produtos/anuario-brasileiro-de-seguranca-publica/7aedicao.

OLIVEIRA, Luciano. Polícia e classes populares. Cadernos de Estudos Sociais. Recife, 1 (1): 85-94, jan./jun. 1985.

OLIVEIRA, Paulo Roberto Batista de. Direitos Fundamentais e Preservação da Ordem Pública: Um estudo sobre a atividade de policiamento ostensivo desenvolvida pela Polícia Militar do Distrito Federal. Dissertação de Mestrado. Brasília: UnB, 2007.

PORTAL G1-GLOBO. Mais uma chacina no Rio de Janeiro. Disponível em: http://g1.globo.com/rio-de-janeiro/noticia/2015/11/cinco-jovens-sao-mortos-no-rio-eparentes-das-vitimas-culpam-pm.html. Acessado em 29 nov. 2015.

PORTO, Maria Stela Grossi e COSTA, Arthur Trindade Maranhão. Condutas Policiais e Códigos de Deontologia: o controle da atividade policial no Brasil e no Canadá. Brasília, Ed. UnB, 2014.

RATTON JR, José Luiz de Amorim. Violência e Crime no Brasil Contemporâneo. Brasília: Cidade Gráfica e Editora, 1996.

SILVA, Guilherme Fernando Ferreira da. A Concepção Criminológica de Durkheim - um Criminoso Social. Trabalho de Conclusão de Curso. Ponta Grossa: Faculdade União, 2009. 
SOUZA, E. R. Homicídios no Brasil: O grande vilão da saúde pública na década de 80 . Cadernos de Saúde Pública. Rio de Janeiro (supl. 1): 45-60, 1994.

TOCANTINS. Polícia Militar: Competências - Atribuições. Disponível em http://pm.to.gov.br/institucional/a-corporacao/competencias-atribuicoes/. Acesso em 20 nov. 2015.

WAISELFISZ, Julio Jacobo. Mapa da Violência 2012: os novos padrões da violência homicida no Brasil. São Paulo: Instituto Sangari, 2011. 